\title{
A COMPARATIVE STUDY ON EVALUATION OF ULTRASOUND AND COMPUTED TOMOGRAPHY IN THE DIAGNOSIS OF OVARIAN TUMOURS AND ITS CORRELATION WITH LAPAROTOMY SURGICAL STAGING AND HISTOPATHOLOGY
}

\author{
Uma Devi Kavali ${ }^{1}$ D. Hemalatha Devi
}

${ }^{1}$ Consultant Gynaecologist, Fertility Specialist, Vignesh Test Tube Baby Centre, Tanuku, Andhra Pradesh, India.

2Professor, Department of Obstetrics and Gynaecology, Andhra Medical College, Visakhapatnam, Andhra Pradesh, India.,

\begin{abstract}
BACKGROUND
Ultrasound and computed tomography play an important role in the diagnosis, preparative staging, surgical treatment and evaluation of tumour recurrence of ovarian carcinoma. Ovarian carcinoma has characteristic tumour appearances and modes of tumour spread within the peritoneal cavity. By recognising these features, the radiologist can assist the clinicians in treatment planning. In view of this, we thought to compare the advantages of most practically feasible investigations like ultrasound and computed tomography in making early diagnosis of ovarian tumours and its correlation with laparotomy with surgical staging and histopathology subsequently.

Aims and Objectives- To compare and analyse the diagnostic features of ovarian tumours through Ultrasound and CT preoperatively and its correlation with laparotomy with surgical staging and histopathology postoperatively.
\end{abstract}

ABSTRACT

\section{MATERIALS AND METHODS}

A prospective analysis was done of 100 cases from September 2010 to September 2012, i.e. a period of 2 years. A detailed imaging evaluation was done with the help of USG and CT and subsequently followed up with intraoperative and postoperative HPE findings. The data was analysed using SPSS version 24 and results tabulated.

\section{RESULTS}

Among 100 cases, $74 \%$ were benign and 26\% were malignant tumours. Benign tumours were more common in 31 - 40 years' age group (33.7\%). Malignant tumours were more common in 51 - 60 years' age group (26.9\%). In our study, both benign and malignant tumours are more common in multiparous. Most common benign tumour is mucinous cystadenoma (58.1\%). Most common malignant tumour is papillary serous cystadenocarcinoma (30.7\%). Most of the patients presented with pain abdomen followed by mass per abdomen in both benign and malignant. Among 100 cases, USG identified 75 cases as benign and 25 cases as malignant. Among 100 cases, CT identified 74 cases as benign and 26 cases as malignant.

\section{CONCLUSION}

Sensitivity and specificity of CT in detecting ovarian tumour is more compared to USG. Although, CT is superior to USG in evaluating ovarian tumours, USG should be the initial screening procedure, because it is highly sensitive though not specific in characterisation of nature of benign tumours.

\section{KEY WORDS}

Benign, Malignant Ovarian Tumours, Ultrasound, Computed Tomography.

HOW TO CITE THIS ARTICLE: Kavali UD, Devi DH. A comparative study on evaluation of ultrasound and computed tomography in the diagnosis of ovarian tumours and its correlation with laparotomy surgical staging and histopathology. J. Evolution Med. Dent. Sci. 2018;7(25):2961-2966, DOI: 10.14260/jemds/2018/667

\section{BACKGROUND}

Ovarian tumours account for $30 \%$ of all cancers of female genital tract. Ovarian cancer is the second most common of all genital cancers and account for 10 to 15 percent of all Gynaecological cancers in developing countries including India. ${ }^{1}$ Of all the gynaecologic cancers, ovarian malignancies represent the greatest clinical challenge. $.^{2} 2 / 3^{\text {rd }}$ of the patients are present in the last stage. Prognosis of these patients can be improved with the aid of imaging modalities like ultrasound and computed tomography. Once a pelvic mass is

'Financial or Other Competing Interest': None.

Submission 14-09-2017, Peer Review 01-06-2018,

Acceptance 08-06-2018, Published 18-06-2018.

Corresponding Author:

Dr. D. Hemalatha Devi,

D-14 Doctors Quarters, Maharani Peta,

Visakhapatnam-530002,

Andhra Pradesh, India.

E-mail: hema.vgh.gyn@gmail.com

DOI: $10.14260 /$ jemds $/ 2018 / 667$

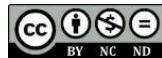

found, the role of the diagnostic radiologic modalities is important to clarify its origin and characteristics. Ultrasound and computed tomography plays an important role in the diagnosis, preoperative staging, surgical treatment and evaluation of tumour recurrence of ovarian carcinoma.

Of all the gynaecological malignancies, ovarian carcinoma is the one least diagnosed at an early stage and is the most common cause of death from gynaecological malignancies.

Ovarian carcinoma has characteristic tumour appearances and modes of tumour spread within the peritoneal cavity. By recognising these features, the radiologist can assist the clinicians in treatment planning.

As benign ovarian tumours greatly outnumber the malignant ones, determination of a degree of suspicion for malignancy is critical and is largely based on imaging modalities. Based on few studies already done, some say that ultrasound is an excellent method for preoperative screening and is the most practical modality available and has high negative predictive value for the diagnosis of ovarian tumours. 
In view of this, we thought to compare the advantages of most practically feasible investigations like ultrasound and computed tomography in making early diagnosis of ovarian tumours and its correlation with laparotomy, with surgical staging and histopathology subsequently.

\section{MATERIALS AND METHODS}

The study was carried on 100 women patients from September 2010 to September 2012, i.e. a period of 2 years, who were attending the Gynaecology and Radiology Department, Government General Hospital, Kakinada, where detailed imaging evaluation was done with the help of USG and CT and then they are subsequently followed up with intraoperative and postoperative HPE findings. With the help of these findings, the sensitivity and specificity of CT and USG in the diagnosis of benign and malignant tumours are calculated.

\section{Ultrasonography}

Transabdominal sonography was carried out with Esaote MyLab 40 ultrasound machine using 3.5 and $5 \mathrm{MHz}$ curvilinear and linear transducers. Scanning in transverse, oblique and sagittal planes were carried out and probable characterisation of ovarian tumours was evaluated.

\section{Advantages}

Ultrasonography is the most useful, non-invasive, inexpensive modality to confirm ovarian mass with no risk of radiation exposure.

Ultrasonography is used to determine the differences between normal physiologic findings, inflammatory changes, benign neoplastic process and ovarian cancer.

Using TVS + Colour Doppler the neovascularisation within malignancies made up of abnormal vessels, lacking smooth muscle within their walls and contains multiple A-V shunts, resulting in low impendence flow can be identified and the following can be calculated-

- Pulsatility Index $<1$ - most accurate.

- $\quad$ Resistivity Index $<0.4$

- The average maximum velocity- $15 \mathrm{~cm} / \mathrm{s}$ and absence of diastolic notch.

USG is used to differentiate solid areas within ovarian tumours from haemorrhage and mucin where CT cannot. It has been shown that USG is $90 \%$ sensitive in detecting pelvic masses and their origins, however considerable overlap is present in imaging features of benign and malignant lesions.

\section{Ultrasonography Features suggestive of Malignant Ovarian Tumours}

1. Hyperechoic solid areas within the mass.

2. Thick $(>3 \mathrm{~mm})$ nodular septations.

3. Size of mass $>7 \mathrm{~cm}$ (although very large, but simple cysts are usually benign).

4. Central rather than peripheral vascularity.

5. $\mathrm{RI}<0.6$ (RI $>0.8$, benign).

6. Presence of papillary projections.

\section{CT-Scan}

In all 100 patients, CT scan of the abdomen was carried out with Siemens Somatom Spiral dual slice CT-scanner.
Pre and post IV contrast images along with oral contrast were taken in the axial planes. Thin sections of 1 - $3 \mathrm{~mm}$ were taken to be the region of interest. Evaluations of pathologies of adjacent anatomical structures in case of malignancy are also called out as a part of CT assessment and with the help of MPR. Currently, CT is considered the most useful preoperative imaging technique with a reported accuracy of 70$80 \%$. This is due to its easier accessibility, quicker imaging and interpretation time physical feasibility and lower cost than MRI. ${ }^{3}$

\section{Advantages}

1. It is easily accessible, quicker imaging, less interpretation time, low cost than MRI.

2. Contrast enhanced CT is helpful in assessing the enhancement patterns of solid areas in ovarian tumours, which characterise their malignancy potential.

3. CT is useful for staging ovarian cancer, to diagnose residual/ recurrent ovarian cancer and for monitoring response to therapy.

4. CT reported (By et al) identification of peritoneal implants as small as $2-3 \mathrm{~mm}$ (where large ascites is seen) and as $5 \mathrm{~mm}$ (without ascites) and lymphadenopathy $>1 \mathrm{~cm}$ in paraaortic, external iliac, obturator and hypogastric nodes due to thin sections and multiplanar imaging.

\section{CT Features Suggestive of Malignant Ovarian Tumours}

1. Thick irregular wall.

2. Thick septa $(>3 \mathrm{~mm})$.

3. Presence of solid component.

4. Large soft tissue component with necrosis.

5. Large and profuse papillary projection.

6. Enhancing solid lesion.

7. Ancillary findings like pelvic organ invasion, implants (Peritoneal, Omental, mesenteric), ascites and adenopathy.

\section{Intraoperative Findings of Malignant Tumours}

1. Ascites.

2. Omental deposits.

3. Involvement of other organs.

4. Contralateral ovarian involvement.

5. Dense adhesions.

6. Variable consistency of the tumour.

7. Coarse papillary projections.

\section{Statistical Analysis}

All data was collected and verified. Collected data was subjected to SPSS (version 24) for analysis. P value of 0.05 was considered significant.

\section{RESULTS}

Total no. of patients are 100. USG and CT were performed in all 100 patients preoperatively followed by intraoperative findings and postoperative HPE. In this study, out of 100 cases $74 \%$ were benign and $26 \%$ were malignant. Findings were confirmed by postoperative HPE. Maximum number of benign tumours was noted in the age group of $31-40$ years (33.7\%). Malignant tumours were more common in $51-60$ years of age group (26.9\%). In our study, ovarian tumours are more common in multipara. 
USG and CT had high accuracy (0.91) for the overall diagnosis of malignancy. In the ovaries, the accuracy of CT imaging (0.91) was higher than that of US (0.78). In the extraovarian pelvis and in the abdomen conventional US and CT imaging had similar accuracies $(0.87-0.95)$. In differentiation of disease confined to the pelvis from abdominal spread the specificity of conventional US (96\%) was higher than that of CT, whereas the sensitivity of CT (92\%) were significantly higher than that of conventional US (75\%).

Statistically significant correlation was found between US and CT, but CT is far better compared to US for operability and pathological changes. Demography and parity details are shown in Table 2 and 3.

In benign tumours most of the patients present with pain abdomen (40.5\%) followed by mass per abdomen (39.1\%) and distension of abdomen (28.3\%), whereas in malignant cases patient presented with pain abdomen (57.6\%) followed by mass per abdomen (38.4\%), distension of abdomen (23.7\%) and loss of appetite (19.2\%).

Clinical symptoms are shown in Table 4.
Most common benign tumour is mucinous cystadenoma (58.1\%) followed by serous cystadenoma (20.2\%) and dermoid (10.8\%). Most common malignant tumours are papillary serous cystadenocarcinoma $(30.7 \%)$ followed by mucinous cystadenocarcinoma (23\%) and serous cystadenocarcinoma (19.2\%).

Out of 26 cases of malignant tumours, stage 1a is $53 \%$, Stage $1 \mathrm{c}$ is $26 \%$, Stage IIIc is $15 \%$ and stage IV are $6 \%$. Most common surgery underwent by these patients were TAH with bilateral salpingo-oophorectomy followed by TAH with right ovariotomy and LSO in $40 \%$ cases and TAH with left ovariotomy and RSO in $21 \%$ cases.

Among 100 cases, USG identified 75 cases as benign and 25 cases as malignant. Among 100 cases CT identified 74 cases as benign and 26 cases as malignant. Sensitivity and specificity rates of USG in identification of benign tumours are $87.8 \%$ and $61 \%$ respectively. In malignant tumours are $61 \%$ and $87.8 \%$ respectively with accuracy rate of $81 \%$. Sensitivity and specificity rates of CT in identification of benign ovarian tumours are $97.2 \%$ and $92 \%$ respectively. In malignant tumours are $92 \%$ and $97.2 \%$ respectively with an accuracy rate of $96 \%$.

\begin{tabular}{|c|c|c|}
\hline & Benign & Malignant \\
\hline Total no. of cases & 74 & 26 \\
\hline Percentage of cases & $74 \%$ & $26 \%$ \\
\hline \multicolumn{2}{|c|}{ Table 1 } \\
\hline
\end{tabular}

Demography details and parity is as shown in Table 2 and 3.

\begin{tabular}{|c|c|c|c|c|}
\hline \multirow{2}{*}{ Age Group in Years } & \multicolumn{2}{|c|}{ Benign Cases (74) } & \multicolumn{2}{c|}{ Malignant Cases (26) } \\
\cline { 2 - 5 } & No. of Cases & Percentage & No. of Cases & 0 \\
\hline $1-10$ & 0 & $0 \%$ & 0 & $0 \%$ \\
\hline $11-20$ & 7 & $9.4 \%$ & 2 & $7.6 \%$ \\
\hline $21-30$ & 14 & $18.9 \%$ & 6 & $23 \%$ \\
\hline $31-40$ & 25 & $33.7 \%$ & 6 & $23 \%$ \\
\hline $41-50$ & 16 & $21.6 \%$ & 7 & $26.9 \%$ \\
\hline $51-60$ & 8 & $10.8 \%$ & 5 & $19.2 \%$ \\
\hline $61-70$ & 4 & $5.4 \%$ & 0 & $0 \%$ \\
\hline $71-80$ & 0 & $0 \%$ & & \\
\hline
\end{tabular}

\begin{tabular}{|c|c|c|c|c|}
\hline \multirow{2}{*}{ Parity } & \multicolumn{2}{|c|}{ Benign Cases } & \multicolumn{2}{c|}{ Malignant Cases } \\
\cline { 2 - 5 } & No. of Cases & Percentage & No. of Cases & Percentage \\
\hline 0 & 10 & $13.5 \%$ & 1 & $3.8 \%$ \\
\hline 1 & 6 & $8.1 \%$ & 3 & $11.5 \%$ \\
\hline 2 & 28 & $37.8 \%$ & 7 & $26.9 \%$ \\
\hline 3 & 15 & $20.2 \%$ & 5 & $30.7 \%$ \\
\hline 4 & 10 & $13.5 \%$ & 0 & $19.2 \%$ \\
\hline 5 & 3 & $4.0 \%$ & 1 & $3.8 \%$ \\
\hline 6 & 2 & $2.7 \%$ & 1 & $3.8 \%$ \\
\hline 7 & 0 & $0 \%$ & & \\
\hline
\end{tabular}

\begin{tabular}{|c|c|c|c|c|c|}
\hline & Symptoms & Benign Cases & Percentage & Malignant Cases & Percentage \\
\hline 1. & Mass per abdomen & 29 & $39.1 \%$ & 10 & $38.4 \%$ \\
\hline 2. & Pain abdomen & 30 & $40.5 \%$ & 15 & $57.6 \%$ \\
\hline 3. & Loss of appetite & 1 & $1.3 \%$ & 5 & $19.2 \%$ \\
\hline 4. & G.I.T. disturbances & 4 & $5.4 \%$ & 1 & $3.8 \%$ \\
\hline 5. & Leucorrhoea & -- & -- & -- & -- \\
\hline 6. & Pressure symptoms & 2 & $2.7 \%$ & 2 & $7.6 \%$ \\
\hline 7. & Bleeding per vagina & -- & -- & -- & -- \\
\hline
\end{tabular}




\begin{tabular}{|c|c|c|c|c|c|}
\hline 8. & Distension of abdomen & 21 & $28.3 \%$ & 6 & $23.7 \%$ \\
\hline 9. & Burning micturition & 1 & $1.3 \%$ & -- & -- \\
\hline 10. & Fever & -- & -- & -- & - \\
\hline
\end{tabular}

\section{Type of Benign Tumours according to H.P.E. Report}

\begin{tabular}{|c|c|c|}
\hline \multirow{2}{*}{ Name of the Benign Tumour } & \multicolumn{2}{|c|}{ In the Present Study } \\
\cline { 2 - 3 } & No. of Cases & Percentage of Total Benign Tumours \\
\hline 1. Serous tumours & 15 & $20.2 \%$ \\
a. Serous cystadenoma & 1 & $1.3 \%$ \\
b. Papillary Serous cystadenoma & 43 & $58.1 \%$ \\
\hline 2. Mucinous cystadenoma & 0 & $0 \%$ \\
\hline 3. Endometrioid tumours & 1 & $1.3 \%$ \\
\hline 4. Brenner & 1 & $1.3 \%$ \\
\hline 5. Fibroma & 4 & $5.4 \%$ \\
\hline 6. Fibrothecoma & 8 & $10.8 \%$ \\
\hline 7. Dermoid & 1 & $1.3 \%$ \\
\hline
\end{tabular}

Type of Malignant Tumours according to H.P.E. Report

\begin{tabular}{|c|c|c|}
\hline Name of the Malignant Tumour & \multicolumn{2}{|c|}{ Incidence in the Present Study Period } \\
\cline { 2 - 3 } & No. of Cases & Percentage of Total Benign Tumours \\
\hline 1. Serous cystadenocarcinoma & 5 & $19.2 \%$ \\
\hline 2. Papillary serous cystadenocarcinoma & 8 & $30.7 \%$ \\
\hline 3. Mucinous cystadenocarcinoma & 6 & $23.0 \%$ \\
\hline Papillary mucinous cystadenocarcinoma & 1 & $3.8 \%$ \\
\hline Pucinous cystadenocarcinoma of borderline malignancy & 3 & $11.5 \%$ \\
\hline 7. Endometrioid carcinoma & 1 & $3.8 \%$ \\
\hline 8. Brenner & 1 & $3.8 \%$ \\
\hline 10. Dysgerminoma & -- & -- \\
\hline 11. Embryonal carcinoma & -- & -- \\
\hline 12. Endodermal sinus tumour & 1 & $3.8 \%$ \\
\hline 13. Malignant teratoma & -- & -- \\
\hline 14. Krukenberg & -- & -- \\
\hline Table 6 & -- & - \\
\hline
\end{tabular}

\begin{tabular}{|c|c|c|}
\hline \multirow{2}{*}{ Type of Surgery } & \multicolumn{2}{|c|}{ Present Study Period } \\
\hline & No. of Cases & Percentage \\
\hline 1. Right ovariotomy & 13 & $13 \%$ \\
\hline $2 . \quad$ Left ovariotomy & 10 & $10 \%$ \\
\hline 3. T.A.H. with right ovariotomy with left salpingo-oophorectomy & 40 & $40 \%$ \\
\hline 4. T.A.H. with left ovariotomy with right salpingo-oophorectomy & 21 & $21 \%$ \\
\hline $\begin{array}{ll}\text { 5. } & \text { T.A.H with bil. ovariotomy } \\
\end{array}$ & 3 & $3 \%$ \\
\hline 6. Right ovariotomy with left salpingo-oophorectomy & 5 & $5 \%$ \\
\hline 7. Left ovariotomy with right salpingo-oophorectomy & 3 & $3 \%$ \\
\hline 8. Ovarian cystectomy & -- & -- \\
\hline 9. Ovariotomy with wedge resection of opposite ovary & -- & -- \\
\hline 10. T.A.H with unilateral ovariotomy & 1 & $1 \%$ \\
\hline 11. Debulking surgery & 4 & $4 \%$ \\
\hline Table 7 & & \\
\hline
\end{tabular}

\begin{tabular}{|c|c|c|}
\hline Name of the Benign Tumour & No. of Cases & Percentage of Total Benign Tumours \\
\hline 1. Serous tumours & 15 & $20.2 \%$ \\
a. Serous cystadenoma & 1 & $1.3 \%$ \\
\hline b. Papillary serous cystadenoma & 43 & $58.1 \%$ \\
\hline 2. Mucinous cystadenoma & 0 & $0 \%$ \\
\hline 3. Endometrioid tumours & 1 & $1.3 \%$ \\
\hline 4. Brenner & 1 & $1.3 \%$ \\
\hline
\end{tabular}




\begin{tabular}{|c|c|c|}
\hline 6. Fibrothecoma & 4 & $5.4 \%$ \\
\hline 7. Dermoid & 8 & $10.8 \%$ \\
\hline 8. Granulosa cell tumours & 1 & $1.3 \%$ \\
\hline \multicolumn{2}{|c|}{ Table 8 } \\
\hline
\end{tabular}

\begin{tabular}{|c|c|c|c|c|c|c|}
\hline & $\begin{array}{c}\text { Benign Cases in } \\
\text { HPE }\end{array}$ & $\begin{array}{c}\text { Benign } \\
\text { Cases in USG (TP) }\end{array}$ & $\begin{array}{c}\text { Malignant Cases } \\
\text { in HPE }\end{array}$ & $\begin{array}{c}\text { Malignant Cases in } \\
\text { USG (TP) }\end{array}$ & Sensitivity & Specificity \\
\hline USG & 74 & 65 & 26 & 16 & $81 \%$ & $96 \%$ \\
\hline CT & 74 & 72 & 26 & 24 & $97.2 \%$ & $92 \%$ \\
\hline \multicolumn{7}{|r|}{ Table 9 } \\
\hline
\end{tabular}

\section{DISCUSSION}

Ovarian tumours present a greatest clinical challenge of all gynaecological cancers and ovarian carcinoma is the second most common gynaecological carcinoma in incidence. As most of them present in a late stage, clinical diagnosis alone is difficult and as benign ovarian tumours greatly outnumber malignant ones, determination of a degree of suspicion for malignancy is critical and is based largely on imaging modalities, which will help in early diagnosis to reduce mortality and morbidity.

Ultrasonography is considered the primary imaging modality for the evaluation of suspected adnexal mass, because of its wide spread availability and high sensitivity in the detection of mass. ${ }^{4,5}$

Recent innovations in multidetector computed tomography (MDCT) which allows thinner sections, faster imaging and good spatial resolution, has led to its more common use for further characterisation of adnexal mass and staging work-up of ovarian malignancy.6,7,8

In view of this, we thought to compare the advantages of most practically feasible investigations like USG and CT in making early diagnosis of ovarian tumours and its correlation with laparotomy surgical staging and HPE subsequently.

The sensitivity and specificity rate of USG and CT in diagnosing benign and malignant ovarian tumours were calculated and computed. They are also compared with studies done in U.S.A and U.K.

In this study done on 100 patients with clinical suspicion of ovarian tumours, all of them were subjected to USG and CT and subsequently followed by intraoperative and postoperative HPE findings. The result of this study done on benign and malignant nature of ovarian tumours is based on postoperative HPE findings and cases are analysed.

As per Table No. 2, 25 benign cases (33.7\%) and 06 malignant cases $(23 \%)$ were in the age group of 31 - 40 years and are multiparous. As per the symptoms according to Table No. 4, 30 patients i.e. $40.5 \%$ presented with pain abdomen, followed by 29 patients (39.1\%) with mass per abdomen and 21 cases $(28.3 \%)$ with abdominal distension, others by pressure symptoms (2.7\%), GI disturbances (5.4\%), loss of appetite (1.3\%), and burning micturition (1.3\%).

As shown in Table No. 5 of the present study, 43 cases (58.1\%) are mucinous cystadenoma followed by serous cystadenoma 16 cases (21.5\%), others are Brenner (1.3\%), Fibroma (1.3\%), Fibrothecoma (5.4\%), Dermoid (10.8\%) and Granulosa cell tumour (1.3\%).

According to Table No. 6, most common malignant tumour is papillary serous cystadenocarcinoma in 8 cases (30.7\%) followed by mucinous cystadenocarcinoma in 6 cases $(23 \%)$, others are serous cystadenocarcinoma in 5 cases $(19.2 \%)$, papillary mucinous cystadenocarcinoma in one case $(3.8 \%)$, mucinous cystadenocarcinoma of Borderline Malignancy in 3 cases (11.5\%), Papillary Serous cystadenocarcinoma of Borderline Malignancy in 1 case (3.8\%), endometrioid carcinoma in 1 case $(3.8 \%)$ and Dysgerminoma in 1 case (3.8\%).

Benign tumours were more common in age group of 3140 years $(33.7 \%)$ and malignant tumours in 50-60 years (26.9\%).

Based on imaging findings, these patients underwent surgery. Most of the patients underwent T.A.H with right ovariotomy and left salpingo-oophorectomy (40\%) followed by T.A.H. with left ovariotomy with Right salpingooophorectomy (21\%) and Right ovariotomy (13\%), Left ovariotomy (10\%), T.A.H. with bilateral Ovariotomy (3\%), right Ovariotomy with left Salpingo-oophorectomy (5\%), left Ovariotomy with right Salpingo-oophorectomy (3\%), T.A.H. with unilateral Ovariotomy (1\%), Debulking Surgery (4\%) as shown in Table No. 7. The malignant cases thus diagnosed by imaging correlated with intraoperative findings like variable consistency of tumour, dense adhesions, attachment to omentum and adjacent structures, and omental attachment was seen.

According to surgical staging, 14 cases (53\%) are of stage $1 \mathrm{~A}, 7$ cases $(26 \%)$ are of Stage $1 \mathrm{C}, 4$ cases $(15 \%)$ are of Stage III-C, 1 case $(6 \%)$ was of Stage IV.

According to Ultrasound findings, 75 cases detected as benign and 25 cases as malignant. According to CT findings, 74 cases were detected as benign and 26 cases were detected as malignant. According to HPE findings, 74 confirmed as benign and 26 confirmed as malignant.

\section{CONCLUSION}

CT is definitely superior to USG in determining the nature of ovarian tumours. In recent years, the improved spatial resolution and contrast sensitivity available with current CT scanners has increased their capability for evaluation, the benign and malignant nature of ovarian tumours, although it requires the use of IV contrast and exposes the patient to ionising radiation. Sensitivity and specificity of CT in detecting ovarian tumours is more compared to USG.

Overall accuracy rate of CT in detecting ovarian tumours is $96 \%$ when compared to $81 \%$ by USG. Although, CT is superior to USG in evaluating ovarian tumours, USG should be the initial screening procedure, because it is highly sensitive though not specific in characterisation of nature of benign tumours, non-requirement of contrast material, lack of ionising radiation and good sensitivity rates. USG is a good initial imaging modality of choice.

In conclusion, unilocular ovarian cyst seems to carry a very slight chance of malignancy, even in women over the age 
of 40. Papillary vegetation on the cyst wall, a structure that can be seen by ultrasound, seems to be a serious sign. ${ }^{9}$

Ovarian cancer is an insidious and intractable disease. Late diagnosis by traditional techniques, and paucity of early and specific symptoms is probably the main reason for poor prognosis. Despite advances in treatment, ovarian cancer has constantly had the highest fatality ratio of all gynaecological malignancy with a 5-year survival rate of all stages of $40 \%$ $50 \% .^{10,11}$

\section{REFERENCES}

[1] Padubidri VN, Daftary SN. Howkins \& Bourne Shaw's text book of Gynaecology. Chapter $-29.15^{\text {th }}$ edn. Haryana: Elsevier Science 2010: p. 422.

[2] Berek JS, Rinehart RD, Paula J, et al. Berek and Novak's Gynaecology. Chapter - 32. Section 6. $13^{\text {th }}$ edn. Philadelphia, PA: Lippincott Williams \& Wilkins 2007: p. 506.

[3] Grainger RG, Allison DJ. Imaging in Gynaecology. In: White House $\mathrm{GH}$, Wright $\mathrm{CH}$, eds. Grainger and Allisaons diagnostic radiology. A text book of medical imaging. $4^{\text {th }}$ edn. Churchill Livingstone 2004: p. 221521.

[4] Salem S, White LM, Lai J. Doppler Sonography of adnexal masses: the predictive value of the pulsatility index in benign and malignant decease. AJR Am J Roentgenol 1994;163(5):1147-1150.
[5] Spencer JA, Ghattamaneni S. MR Imaging of the sonographically indeterminate adnexal mass. Radiology 2010;256(3):677-94.

[6] Tsili AC, Tsampoulas C, Charisiadi A, et al. Adnexal masses: accuracy of detection and differentiation with multidetector computed tomography. Gynecol Oncol 2008;110(1):22-31.

[7] Zhang J, Mironov S, Hricak H, et al. Charactarization of adnexal masses using feature analysis at contrastenhanced helical computed tomography. J Comput Asst Tomogr 2008;32(4):533-40.

[8] Tsili AC, Tsampoulas C, Argyropoulou M, et al. Comparative evaluation of multidetector CT and MR imaging in the differentiation of adnexal masses. Eur Radiol 2008;18(5):1049-57.

[9] Granberg S, Wikland M, Jansson I. Macroscopic characterization of ovarian tumours and the relation to the historical diagnosis: criteria to be used for ultrasound evaluation. Gynecol Oncol 1989;35(2):13944.

[10] Kuiperv M, Peakman M, Farzaneh F. Ovarian tumour antigens as potential targets for immune gene therapy. Gene Ther 1995;2(1):7-15.

[11] Laframboise S, Nedelcu R, Murphy J, et al. Use of CA 125 and ultra sound in high risk women. Int J Gynecol Cancer 2002;12(1):86-91. 